\title{
UNDERSTANDING SOURCE INCOMPATIBILISM
}

\author{
Neal A. Tognazzini
}

\begin{abstract}
Source incompatibilism is an increasingly popular version of incompatibilism about determinism and moral responsibility. However, many self-described source incompatibilists formulate the thesis differently, resulting in conceptual confusion that can obscure the relationship between source incompatibilism and other views in the neighborhood. In this paper I canvas various formulations of the thesis in the literature and argue in favor of one as the least likely to lead to conceptual confusion. It turns out that accepting my formulation has some surprising (but helpful) taxonomical consequences.
\end{abstract}

Recently, many incompatibilists about determinism and moral responsibility have begun calling themselves 'source incompatibilists,' mostly to distinguish themselves from those incompatibilists who focus exclusively on whether determinism rules out the infamous ability to do otherwise. But while those who call themselves 'source incompatibilists' are united in the desire to distinguish themselves from the more traditional sort of incompatibilist, their thesis cannot be understood merely in terms of what it is not. To understand source incompatibilism fully, the thesis needs some positive content. And it is in the attempt to formulate positive content where theorists divide. As a result, when someone claims to be a source incompatibilist, one always has to ask the follow-up question: "What do you mean by 'source incompatibilism'?" before one can understand the claim. This situation is less than ideal.

The aim of this essay is to eliminate the need for this follow-up question by proposing a particular taxonomy that gives source incompatibilism a stable positive content and also situates it within the neighborhood of incompatibilist views. The central contention is that adopting the taxonomy proposed in this paper will maximize conceptual clarity.

\section{TWO POINTS OF CLARIFICATION}

To begin, it's important to make two points of clarification. First, incompatibilists (of any stripe) do not have a monopoly on the concept of sourcehood. Indeed, any plausible theory of moral responsibility will include an account of control that requires the agent in question to be the source, in some sense, of his or her action. The following, then, is an utterly uncontroversial thesis:

Sourcehood An agent, $S$, is morally responsible for a particular action, $A$, only if $S$ is the source of $A$. 
Part of what makes it uncontroversial, though, is the fact that it remains neutral with regard to any particular conception of sourcehood. Each theorist will have his or her own opinion about how best to understand what's involved in sourcehood.

A proponent of agent-causation, for instance, will understand sourcehood in terms of an agent's literally being the uncaused cause of his or her action (e.g., O'Connor 2000). A proponent of event-causal libertarianism will perhaps understand sourcehood in terms of chaotically amplified indeterminacies culminating in an indeterminate effort to make both of two mutually exclusive choices (e.g., Kane 1996). A compatibilist may understand sourcehood in terms of mechanism-ownership that comes about through a process of taking responsibility for one's mechanism (e.g., Fischer and Ravizza 1998). But however sourcehood is understood, all parties agree that it is required for moral responsibility. Where they differ is with respect to what sourcehood consists in.

Any initial temptation to think that sourcehood is an exclusively incompatibilist notion comes from conflating sourcehood with what some incompatibilists have called ultimate sourcehood. Whereas an agent is the source of an action insofar as the agent exercises some appropriate form of active control over the action, in order for an agent to be the ultimate source of an action, the agent must have control over certain other aspects of the world, too. For instance, perhaps the agent must exercise control over any sufficient cause of the action in question, as well as over the action itself. Or perhaps the agent must exercise control over his or her character or personality. Whatever the details, though, ultimate sourcehood is only one particular conception of the more general concept of sourcehood, and the two shouldn't be equated. We shall return to this idea of ultimate sourcehood below, but for now let us merely note that one need not think that sourcehood requires any sort of ultimacy. With that in mind, let's continue with our project of giving positive content to the thesis of source incompatibilism.

\section{FIVE FORMULATIONS OF SOURCE INCOMPATIBILISM}

Let's start by familiarizing ourselves with some of the more standard terminology in the debate. Compatibilists and incompatibilists alike agree that sourcehood is required for moral responsibility, but they will disagree about something, namely whether the following two theses are compatible:

(D) There is at any instant exactly one physically possible future. ${ }^{1}$

(M) Some people are on some occasions morally responsible for their actions.

Incompatibilists will say that (D) and (M) could not both be true- this is what makes them incompatibilists. Compatibilists will say that (D) and (M) could

\footnotetext{
${ }_{1}^{1}$ A physically possible future is a way the world could unfold that is consistent both with the actual past and the actual laws of nature. This statement of determinism is to some extent metaphorical, but no less serviceable because of that. The statement of (D) is from Peter van Inwagen $(1983,3)$.
} 
both be true - this is what makes them compatibilists. Now, there are further debates within each camp about the following principle (see Frankfurt 1969):

(PAP) An agent, $A$, is morally responsible for some particular action, $X$, only if $A$ had the ability to refrain from doing $X$.

Some compatibilists embrace (PAP); some don't. Those that do have sometimes been called 'traditional compatibilists' (e.g., Lewis 1981); those that don't have sometimes been called 'semi-compatibilists' (e.g., Fischer 1994). ${ }^{2}$ Some incompatibilists embrace (PAP); some don't. Those that do have sometimes been called 'leeway incompatibilists' (e.g., van Inwagen 1983); those that don't have sometimes been called 'source incompatibilists' (e.g., Stump 2003). So we have arrived at one way of understanding the thesis of source incompatibilism: as the conjunction of incompatibilism with the denial of (PAP).

In one passage, Michael McKenna $(2001,40)$ seems to construe source incompatibilism in this way:

[Source incompatibilists] agree with the semicompatibilists that the Frankfurt examples succeed in showing that the freedom crucial for moral responsibility does not require alternative possibilities . . . But unlike the semicompatibilists, these source incompatibilists maintain that morally responsible agency requires a deterministic break in the actual sequence of events that leads to an agent's freely willed action. $^{3}$

And although he doesn't use the term 'source incompatibilism' explicitly, Randolph Clarke seems to be talking about the same view when he says: "Another group of writers who accept Frankfurt's argument nevertheless maintain that responsibility is incompatible with determinism" (Clarke 2003, 11). So our first formulation of the thesis of source incompatibilism is as follows:

(SI-1) Incompatibilism is true and (PAP) is false.

This formulation captures what many people see as one of the defining features of source incompatibilism: the contrast that it provides to the more traditional sort of incompatibilism that is motivated by (PAP) together with the claim that determinism would rule out the ability to do otherwise.

The next formulation can be distilled from the following passage from Derk Pereboom $(2008,1)$ :

I oppose a type of incompatibilism according to which the availability of alternative possibilities is the most important factor for explaining moral responsibility, and accept instead a variety that ascribes the

\footnotetext{
2 Officially, semi-compatibilism doesn't assert that (PAP) is false. Rather, it simply asserts that (D) and $(\mathrm{M})$ are compatible whether or not determinism rules out the ability to do otherwise. But the most prominent semi-compatibilist_-John Martin Fischer-is also a prominent defender of the claim that (PAP) is false.

3 The term 'source incompatibilism' can be traced back to this paper, though the idea had been around for much longer. You can see early hints of it in John Martin Fischer's (1982) work.
} 
most significant explanatory role to the way in which the agent actually produces the action. In metaphysical terms, the sort of free will required for moral responsibility does not consist most fundamentally in the availability of alternative possibilities, but rather in the agent's being the causal source of her action in a specific way. Accordingly, I advocate source as opposed to leeway incompatibilism.

This understanding of source incompatibilism is different from (SI-1). Rather than having source incompatibilists by definition take an explicit stand on whether (PAP) is true, as (SI-1) has it, Pereboom maintains that source incompatibilists are those incompatibilists who think that causal history is in some sense more important to explaining moral responsibility than is the ability to do otherwise. Let's regiment this formulation of the thesis as follows:

(SI-2) Incompatibilism is true and (regardless of whether (PAP) is true) the ability to refrain from doing $X$ is not what plays the most important role in explaining why $A$ is responsible for doing $X$-what plays the most important role is the causal history of the action.

Some seem to think that an advantage of this formulation is that it allows us to construct a parallel compatibilist position, as well. This position has been called 'source compatibilism,' and it is exactly the same as (SI-2) except that the first conjunct is replaced with "Compatibilism is true" instead. ${ }^{4}$ Below we will consider whether the alleged advantages of (SI-1) and (SI-2) are in fact advantageous.

The next formulation is found explicitly in the work of John Martin Fischer, though apparently endorsed by others. ${ }^{5}$ In a section of one of his papers marked 'Source Incompatibilism,' Fischer writes:

Other philosophers have disagreed [with the view that causal determination in the actual sequence does not rule out moral responsibility], contending that causal determinism in the actual sequence rules out moral responsibility "directly" (and not in virtue of expunging alternative possibilities). (Fischer 2006, 201)

In this passage, Fischer appears to count any incompatibilist view that doesn't rely on the importance of the ability to do otherwise to establish incompatibilism as a source incompatibilist view. Thus:

(SI-3) Incompatibilism is true, but not because determinism rules out the ability to do otherwise.

\footnotetext{
${ }^{4}$ Derk Pereboom, for example, uses the term 'source compatibilism' (see Pereboom 2006; Pereboom 2008; Fischer, et al. 2007).

${ }^{5}$ Something like this formulation is also found in Joseph Keim Campbell's (2006) discussion of source incompatibilism. A previous version of Campbell's paper was presented at the 2006 Inland Northwest Philosophy Conference under the name "Farwell to Source Incompatibilism." Campbell has since modified the name, perhaps to deal with some worries that plague the next formulation discussed in the text. (Further discussion of the view can be found in Campbell's [2011] book, especially ch. 4.)
} 
According to this formulation, there are different ways to argue for the thesis of source incompatibilism. One might argue, for instance, that incompatibilism is true because determinism would preclude the sort of self-creation that theorists like Galen Strawson (1986) seem to think is required for moral responsibility. Or one might argue that incompatibilism is true because some sort of Transfer of Non-Responsibility principle is true, according to which if no one is responsible for the fact that $p$ and no one is responsible for the fact that $p$ implies $q$, then no one is responsible for the fact that $q .{ }^{6}$ All that is important, according to (SI-3), is that the source incompatibilist not argue for incompatibilism via (PAP).

Note that (SI-3) is distinct from (SI-1), despite the fact that they both involve some claim about (PAP). Whereas (SI-1) has it that the source incompatibilist is committed to the falsity of (PAP), (SI-3) merely requires that the source incompatibilist not think (PAP) is part of the reason why determinism precludes moral responsibility. It's compatible with (SI-3), then, that some source incompatibilist could nevertheless think that (PAP) is true.

Whereas (SI-3) provides only information about something that does not threaten moral responsibility, the fourth formulation takes a more positive route. Consider the following quotation from Michael McKenna (2001, 40):

[Source incompatibilists] hold that the fundamental threat to moral responsibility from determinism derives, not from the thought that in a deterministic world an agent cannot do otherwise; it derives, instead, from the thought that, if determinism is true, an agent's actions do not originate in her.

According to this formulation, source incompatibilism takes a stand not only on what it is about determinism that threatens moral responsibility, but also on what is the more fundamental threat from determinism. We can regiment this formulation as follows:

(SI-4) Incompatibilism is true, and the fundamental reason it is true is that determinism rules out origination - not that determinism rules out the ability to do otherwise.

It is important to note that (SI-4) is distinct from (SI-2), despite the fact that they both involve claims about importance or fundamentality. Whereas (SI-2) states that the causal history of an action plays the more important role in explaining some agent's moral responsibility for that action, (SI-4) merely states that facts about causal history constitute the fundamental reason that determinism rules out moral responsibility. One is a claim about what explains an agent's moral responsibility; the other is a claim about why incompatibilism is true.

Finally, a fifth formulation can be found in the following quotation from Kevin Timpe (2007, 143):

\footnotetext{
${ }_{6}$ Mark Ravizza (1994) has discussed such a Transfer Principle at length, and more discussion can be found in his work with John Martin Fischer (Fischer and Ravizza 1998, ch. 6).
} 
At the heart of Source Incompatibilism is the claim that moral responsibility requires that an agent is the ultimate source of that action; and Source Incompatibilists think that the truth of causal determinism would imply that no one would be the ultimate source of her actions. ${ }^{7}$

Setting aside the adjective 'ultimate' for now (it will come up again later), we can use Timpe's quotation as the foundation for our fifth formulation of the source incompatibilist thesis. Nothing is mentioned here about (PAP) one way or the other, and nothing is mentioned about what plays the more important role in explaining an agent's moral responsibility or what is the more fundamental reason determinism rules out moral responsibility. ${ }^{8}$ All that is mentioned is a necessary condition for moral responsibility - sourcehood - and the idea that determinism is incompatible with that necessary condition. We can regiment this is as follows:

(SI-5) Incompatibilism is true because determinism rules out sourcehood, which is required for moral responsibility.

These five formulations of the thesis may not be the only extant formulations, but they do seem to represent those that have been most influential.

The claim is not that these formulations are mutually exclusive in the sense that if one is true, the others are automatically false. It could very well be, for instance, that someone accepts the truth of two or three of them. Rather, the claim is that they are mutually exclusive in the sense that at most one can be the best way to understand source incompatibilism. In what follows, I will argue that the best formulation - and 'best' here means 'least likely to lead to conceptual confusion' - is (SI-5). Understanding the thesis in this way, however, will lead to some potentially surprising consequences about who should and should not count as a source incompatibilist, and about the relationships between distinct varieties of incompatibilism.

\section{CONSTRAINTS FOR A FORMULATION}

Let's begin by laying down some constraints for the investigation to follow. Given that we are attempting to formulate the thesis of source incompatibilism, any adequate formulation must conform to two extremely natural constraints. And, as we will see, all of the formulations given above, save one, violate at least one of these constraints. The first constraint can be put as follows:

(C1) Source incompatibilism must be a variety or type of incompatibilism.

This constraint needs to be spelled out in two ways. First, it requires that all source incompatibilists be incompatibilists. That is, in order for someone to be

\footnotetext{
7 See also Timpe's (2008) book on free will, especially ch. 1.

8 Elsewhere in his article, however, Timpe does seem to formulate the source incompatibilist view more along the lines of (SI-4), with its explicit talk about fundamentality. See, for instance, p. 147.
} 
considered a source incompatibilist, she must accept that no deterministic world contains morally responsible agents. That seems natural enough. It is, after all, supposed to be a variety of incompatibilism.

But second, and more important, a proper formulation of source incompatibilism must not smuggle in any views that aren't clearly relevant to the thesis of incompatibilism. That is, for any formulation to count as adequate, it must only take an official stand on views that are clearly relevant to the incompatibility of determinism and moral responsibility. Incompatibilism is not, after all, a positive view about all the necessary and sufficient conditions for moral responsibility - it is merely the view that determinism and moral responsibility are not compossible. So any genuine type or variety of incompatibilism must stick to the basics. It must not take a stand on any necessary or sufficient condition for moral responsibility, unless the condition in question plays an essential role in motivating incompatibilism. Types of incompatibilism should be individuated by what condition for moral responsibility determinism supposedly rules out, and not by any other conditions that aren't relevant to the incompatibility of determinism and moral responsibility. Any genuine variety of incompatibilism will therefore need to fit the following schema: "Incompatibilism is true because

To clarify (C1), consider the predicate 'tall professor.' This phrase does not pick out a type or a variety of professor. It just combines two facts about someone-he is both tall and a professor. But these facts are, in an important sense, independent of each other. One could, with equal propriety, say of the person in question either that he is a tall professor or that he is both tall and a professor. The term 'source incompatibilism,' on the other hand, should not function like this. It shouldn't be that a source incompatibilist is just someone who happens to be both an incompatibilist and an adherent of some other independent thesis. ${ }^{9}$ Rather, it should function more like 'associate professor': the adjective modifying 'professor' in this case is actually relevant to the noun it modifies. One could not, with equal propriety, say of someone either that he is an associate professor or that he is both associate and a professor. Indeed, the latter claim doesn't even seem to make sense. To be an associate professor is to be a particular sort of professor. Similarly, to be a source incompatibilist is to be a particular sort of incompatibilist.

It might be helpful to consider the following remarks from Peter van Inwagen. About the terms 'soft determinism,' 'hard determinism,' and 'libertarianism,' he says:

I object to these terms because they lump together theses that should be discussed and analysed separately. Even having them on hand is a permanent temptation to conflate [the problem of figuring out whether determinism is true or whether we have free will] and [the

\footnotetext{
${ }_{9}$ Though one may be correctly described as a materialist incompatibilist if one accepts both the thesis of materialism and the thesis of incompatibilism, materialist incompatibilism is not a variety or type of incompatibilism.
} 
problem of figuring out whether determinism is compatible with free will]. They are therefore worse than useless and ought to be dropped from the working vocabulary of philosophers. (van Inwagen 1983, 14)

These remarks seem quite sensible to me. ${ }^{10}$ And one could make similar remarks if the philosophical community began to use the term 'source incompatibilism' to refer to the conjunction of two theses that ought to be discussed and analyzed separately. Just as hard determinism is not, properly speaking, a variety or type of determinism, so source incompatibilism, in this objectionable sense, would not be a variety or type of incompatibilism. It would just be the conjunction of incompatibilism with some other thesis.

So, (C1) mandates that source incompatibilism must be a type of incompatibilism. But a proper formulation of the thesis must also respect this second constraint:

(C2) Source incompatibilism must be concerned with sourcehood.

This constraint seems unobjectionable. Source incompatibilism is a type of incompatibilism, and that which makes it a type of incompatibilism must have something to do with this concept of sourcehood that is so important to all parties in the debate.

\section{SEARCHING FOR A FORMULATION}

There are five different formulations to consider. All but one of these formulations, it turns out, violate at least one of our two constraints. Consider (SI-1):

(SI-1) Incompatibilism is true and (PAP) is false.

Anyone who endorsed (SI-1) would indeed endorse incompatibilism, since that is the first conjunct of the formulation. However, the second conjunct is unrelated to incompatibilism per se. Recall that according to (PAP), an agent is morally responsible for an action only if the agent is able to refrain from performing that action. But what does the denial of (PAP) have to do with incompatibilism? Nothing at all. It's not as if the denial of (PAP) will play the role of a premise in some argument to the conclusion that determinism and moral responsibility could not both be true (how could it?) ${ }^{11}$ To be sure, many incompatibilists will want to deny (PAP) when they attempt to provide a comprehensive theory of moral responsibility, but the fact that they deny it is entirely orthogonal to the fact that they are incompatibilists. So it looks like (SI-1) runs

\footnotetext{
${ }^{10}$ In more recent work, van Inwagen has repeated this advice: "Although the terms 'libertarianism,' 'hard determinism,' and 'soft determinism' are perfectly well defined, I very strongly recommend that philosophers never use them - except, of course, when they are forced to because they are discussing the work of philosophers who have been imprudent enough to use them .... Writers on free will who do not take my advice on this matter are continually saying things that they would be better off not saying ... " (van Inwagen 2008, 331).

${ }^{11}$ The affirmation of (PAP) may play this role, however, as it does for so-called leeway incompatibilists, who are discussed below.
} 
afoul of $(\mathrm{C} 1)$ and must therefore be rejected.

What of (SI-1)'s alleged advantage that it allows for a clean contrast with the more traditional sort of incompatibilism that is motivated by (PAP) together with the claim that determinism would rule out the ability to do otherwise? This is not, in fact, an advantage. As will be seen in more detail below, this particular contrast is unnecessary, and there's no reason to think that it would be helpful. If all one knows about some theorist is that she is an incompatibilist who denies (PAP), one still doesn't know anything about why she is an incompatibilist; at best, one knows that she's not one because of PAP. But how useful is that knowledge?

Moreover, there is a worry that (SI-1) would tempt some theorists into thinking something false, namely that those who do endorse (PAP) aren't worried about any issues having to do with sourcehood. Just as incompatibilists don't have a monopoly on the concept of sourcehood, so theorists who deny (PAP) don't have such a monopoly either. Sourcehood will play a crucial role in any plausible theory of moral responsibility, even if it is constructed by someone who also happens to be a proponent of (PAP). ${ }^{12}$

Despite its growing currency in the literature, then, (SI-1) ought to be rejected as an adequate formulation of source incompatibilism. What about (SI-2)?

(SI-2) Incompatibilism is true and (regardless of whether (PAP) is true) the ability to refrain from doing $X$ is not what plays the most important role in explaining why $A$ is responsible for doing $X$-what plays the most important role is the causal history of the action.

Like (SI-1), (SI-2) runs afoul of (C1). First, it states that incompatibilism is true; that much is okay. But it then adds a claim about what plays a more important explanatory role regarding moral responsibility. Even if it were clear what it means for a certain set of conditions to play a more important explanatory role, such a claim plays no straightforward role in motivating incompatibilism. Again, how could it? To take a stand on what plays the most important role in explaining why $S$ is responsible for doing $A$ is not to say anything about why determinism and moral responsibility are incompatible. It may be an interesting bit of biographical information about the theorist in question, and it may be crucial for understanding the theorist's overall theory of moral responsibility, but it's certainly no part of the theorist's incompatibilism, and so ought not to be included in any definition of a variety of incompatibilism. ${ }^{13}$

One alleged advantage of (SI-2) is the fact that it has a parallel compatibilist position, source compatibilism. But if source compatibilism is meant to be a

\footnotetext{
${ }^{12}$ Some of the remarks Kevin Timpe (2007) makes seem to indicate that he is being tempted by the terminology to think that proponents of (PAP) are not concerned with sourcehood.

${ }^{13}$ One might object here that a theorist who tells us what plays the more important explanatory role when it comes to moral responsibility is also implicitly telling us why he is an incompatibilistbecause determinism rules out the set of conditions that play the most important explanatory role when it comes to moral responsibility. Perhaps this is right, but the official formulation of source incompatibilism ought not to rely on what's being said implicitly.
} 
variety of compatibilism, a proper formulation of the thesis will have to respect an analogous version of (C1) above for compatibilism. And the thesis of source compatibilism, as understood by an analogue of (SI-2), will violate (C1) just as (SI-2) does. So the fact that (SI-2) has a parallel formulation in terms of compatibilism is not an advantage after all.

Our first two formulations violate $(\mathrm{C} 1)$, and thus are inadequate. ${ }^{14}$ What about (SI-3)?

(SI-3) Incompatibilism is true, but not because determinism rules out the ability to do otherwise.

It should be immediately clear that (SI-3) won't work because it violates (C2). According to (C2), any adequate formulation of source incompatibilism must employ the notion of sourcehood. But such a notion is nowhere to be seen in (SI-3). Moreover, this formulation violates (C1) as well, since it fails to specify a particular type of incompatibilism. It is certainly an incompatibilist thesis in the sense that anyone who accepted it would automatically count as an incompatibilist, but it fails to say anything in particular about what sort of incompatibilist thesis it is. It states what sort of incompatibilist thesis it's not-but it doesn't provide anything positive that is relevant to incompatibilism.

One might at first think that by telling us what sort of incompatibilist thesis it's not it thereby tells us what sort it is, since there are only two sorts: source and leeway. But, as hinted above and as explained in more detail below, an adequate formulation of source incompatibilism will leave open the possibility of other sorts of incompatibilism besides the familiar source and leeway varieties. For instance, some theorists are incompatibilists because they endorse some sort of transfer of non-responsibility principle. Such an argument certainly has incompatibilism as its conclusion, but nowhere does it mention either the ability to do otherwise or anything about sourcehood. So such a position should not be counted as a source incompatibilist position (or a leeway incompatibilist position either, as we will see below), at least on the conceptual scheme argued for here. Source incompatibilism must be a thesis about sourcehood. ${ }^{15}$

(SI-3) fails to respect the constraints, so let's continue our search for a formulation. Next, consider (SI-4):

(SI-4) Incompatibilism is true, and the fundamental reason it is true is that determinism rules out origination - not that determinism rules out the ability to do otherwise.

\footnotetext{
${ }^{14}$ For what it's worth, (SI-1) also violates (C2) since it says nothing about sourcehood. (SI-2), on the other hand, talks about the causal history of an action, which may well be cashed out in terms of sourcehood.

${ }^{15}$ So, even Joseph Campbell's new name for his paper (see note 5 above) that uses the term 'Direct Source Incompatibilism' (emphasis added) will not do. Endorsing a "direct" argument for incompatibilism (that goes via the transfer of non-responsibility principle) is not enough to be counted as a source incompatibilist. At least, not according to the conceptual scheme of this paper. To be sure, someone might attempt to justify the validity of the relevant transfer principle by talking in terms of sourcehood, but a clean taxonomy should not automatically commit proponents of transfer principles to source incompatibilism, a label they may or may not feel is appropriate.
} 
This formulation gets closer than the first three did. No mention is made here of (PAP), and the focus is on a reason why incompatibilism is true. This all seems promising. But (SI-4) still says more than a formulation of source incompatibilism ought to say. In particular, it points out two different reasons one might think that incompatibilism is true, and takes a stand on which of those two reasons is more fundamental. But even if it were clear what it means for one reason to be more fundamental than another, there's no reason to make source incompatibilists by definition committed to any claim about fundamentality. ${ }^{16}$ In fact, claims about fundamentality would seem to violate $(\mathrm{C} 1)$. What's really doing the work in (SI-4) to motivate incompatibilism is the claim about sourcehood (put here in terms of origination); the claim about fundamentality doesn't seem to make a relevant difference to incompatibilism per se. So let's drop the claim about fundamentality and retain the basic flavor of (SI-4), which is that the reason incompatibilism is true is that determinism rules out sourcehood.

Making this small amendment to (SI-4) brings us to the way that (SI-5) was formulated above:

(SI-5) Incompatibilism is true because determinism rules out sourcehood, which is required for moral responsibility.

This formulation is straightforward and, more importantly, it respects both constraints. Consider (C1) first. As with all the other formulations, anyone who accepted (SI-5) would be an incompatibilist. (SI-5) also specifies a certain type of incompatibilism insofar as it identifies a particular reason for thinking that the incompatibilist thesis is true. It fits the schema specified in section 3 above, namely, "Incompatibilism is true because

Now consider (C2). The problem with (SI-3) was that it didn't talk about sourcehood at all, but this is clearly not a problem with (SI-5). The argument for incompatibilism that it endorses refers to sourcehood. Thus it appears that (SI5) respects both constraints, and should indeed be considered an adequate formulation of source incompatibilism. But this isn't merely an adequate formulation; if any thesis ought to be called 'source incompatibilism,' this is it. It may not look a whole lot different than the other candidate formulations we have considered, but in the rest of this paper, I try to clarify its differences and point out its conceptual advantages.

\section{REFINING THE FORMULATION}

To ensure clarity about (SI-5), it will be helpful to look at the distinction between sourcehood and ultimate sourcehood. In the passage from Kevin Timpe cited above as the inspiration for (SI-5), he uses the term 'ultimate sourcehood' instead of the simpler 'sourcehood.' These two notions are often conflated due to the same accidents of history that have made sourcehood seem like a purely incompatibilist idea. ${ }^{17}$ But—and here's the important point-

${ }^{16}$ Leon and Tognazzini's $(2010,564-565)$ work contains a suggestion about how to understand talk of fundamentality as it is invoked in certain formulations of source incompatibilism. 
source incompatibilists need not think that sourcehood requires ultimacy. ${ }^{18}$ For example, someone might hold that the sort of sourcehood required for moral responsibility is just some sort of hierarchical structure of endorsement à la Harry Frankfurt, but this theorist may nevertheless think that if determinism is true, such a structure cannot exist. ${ }^{19}$ Such a position should (and, on the proposed taxonomy of this paper, would) count as a source incompatibilist position. Perhaps no one in particular holds this position, but a clean taxonomy should surely make room for it, and there would be no room for such a position without a clean distinction between sourcehood and ultimate sourcehood.

That said, however, it does seem to be true that most source incompatibilists think that sourcehood requires something like ultimate sourcehood. It will be useful, then, to have a name for their position. Instead of 'source incompatibilism,' though, which is more general, let us use 'ultimacy incompatibilism.' This view can be formulated as follows:

Ultimacy Incompatibilism (UI) Incompatibilism is true because
determinism rules out ultimacy,
which is required for sourcehood,
which is required for moral respon-
sibility.

Formulating the view in this way makes it clear how (UI) fits together with source incompatibilism in general. (UI) is a particular version of source incompatibilism.

\section{IMPLICATIONS}

If the terrain is mapped as suggested above, a few notable results emerge. First, there are various versions of source incompatibilism, including ultimacy incompatibilism. Second, there will be incompatibilists who endorse neither source incompatibilism nor ultimacy incompatibilism. These will be theorists who endorse some other argument for incompatibilism - perhaps one that takes (PAP) as a premise (more on this view below). And finally, the different varieties of incompatibilism are not exclusive. That is, someone may be both a

\footnotetext{
${ }^{17}$ For example, as more philosophers (particularly incompatibilists) were persuaded by the so-called Frankfurt-examples (Frankfurt 1969), it became necessary for PAP-denying incompatibilists to distinguish themselves from more traditional incompatibilists. They latched onto the concept of sourcehood as a way to do this, and at the same time their commitment to a type of ultimacy was imported into the concept as well.

${ }^{18}$ I use the term 'ultimacy' to mark the generally incompatibilist idea that moral responsibility requires some relatively extreme sort of control that is typically missing from compatibilist accounts, but of course compatibilists may well find that use of the term tendentious. (Thanks to Patrick Todd for helping me to see this point.) This is a fair point, but for my purposes nothing hangs on the precise word we use here. We could call it 'super-duper ultimacy' if that would help.

${ }^{19}$ Although Frankfurt's view of moral responsibility is certainly amenable to a compatibilist line, it's unclear whether Frankfurt himself is a compatibilist. Indeed, some of what Frankfurt says makes it seem as though he is reserving the right to be a source incompatibilist of some "non-ultimacy" variety (Frankfurt 2002, 29). But there are also places where Frankfurt seems to assert the compatibilist thesis more clearly (e.g., Frankfurt 2006, 16).
} 
source incompatibilist and an ultimacy incompatibilist (in fact, being the latter entails being the former), and perhaps some other sort of incompatibilist as well. A brief remark on each of these results is in order.

First, it seems right that there should be more than one way to be a source incompatibilist, given how broad the concept of sourcehood is. Consider, for instance, three theorists who should all be considered source incompatibilists: Galen Strawson, Derk Pereboom, and Robert Kane. Each thinks that determinism rules out sourcehood, but each has a different conception of sourcehood. Strawson (1986) thinks sourcehood requires some sort of impossible self-creation, Pereboom (2001) thinks sourcehood amounts to (at least) a lack of determination by factors beyond one's control and perhaps the presence of some sort of agent-causation, and Kane (1996) thinks that sourcehood is a matter of an agent's being responsible for the sufficient causes of his action (or something close to this). But these three theorists share something in common: they focus their incompatibilism on the worry that determinism poses to sourcehood. They should thus all count as source incompatibilists. And this is true despite the fact that they take different stands on (PAP) and other issues having to do with what else is required for moral responsibility. Again, these other issues will be part of a theorist's positive theory, but they form no part of the theorist's incompatibilism per se. ${ }^{20}$

Second, there will be incompatibilists who are neither source nor ultimacy incompatibilists in the above senses of the terms. Consider an incompatibilist who maintains the following view:

Leeway Incompatibilism (LI) Incompatibilism is true because determinism rules out the ability to do otherwise, which is required for moral responsibility.

A leeway incompatibilist need endorse neither source incompatibilism nor ultimacy incompatibilism. Such a theorist might think that if, per impossibile, determinism did not rule out the ability to do otherwise, it would then pose no threat at all to sourcehood or to moral responsibility. The only thing that motivates this theorist's incompatibilism is the idea that determinism would rule out the ability to do otherwise. So the above formulation of source incompatibilism leaves open plenty of room for those that have traditionally been called 'leeway incompatibilists. ${ }^{21}$

But notice that according to our favored formulations of (LI), (SI), and (UI), the views are not exclusive. There's no reason at all why a leeway incompatibilist could not also be a source incompatibilist. Such a theorist will think that

\footnotetext{
${ }^{20}$ As a matter of fact, Strawson, Pereboom, and Kane would all count as ultimacy incompatibilists, since the sort of sourcehood they think is required for moral responsibility involves some stringent sort of ultimacy condition. But, as was pointed out above, ultimacy incompatibilism should not be identified with source incompatibilism, since there certainly seems to be logical room for an incompatibilist view that takes sourcehood seriously while denying the need for ultimacy.

${ }^{21}$ Why might someone be worried about the threat determinism poses to the ability to do otherwise but not be worried about its implications for sourcehood? Consider the standard argument for the
} 
there are two reasons determinism is threatening to moral responsibility. First, it rules out the ability to do otherwise. And moreover, it rules out sourcehood. ${ }^{22}$

Here the proposed taxonomy makes a significant split from the traditional way of dividing up the incompatibilist territory. Traditionally, one cannot be both a leeway incompatibilist and a source incompatibilist. But this dichotomy usually results from the addition of clauses in the formulation of one or both views that directly violate one of the constraints laid down at the beginning of our investigation. So, for instance, if the formulation talks about what is "more fundamental" or what "plays a more important explanatory role", then (LI) and (SI) will turn out to be mutually exclusive. But, as argued above, there is reason not to include such talk in a proper formulation of either thesis. And once such phrases are banished from a proper formulation, the exclusivity disappears, as well. This is no bad thing: why shouldn't it be possible to endorse more than one route to incompatibilism? At the very least, this possibility shouldn't be ruled out by definition.

\section{OBJECTIONS}

Before concluding, a couple of objections to the taxonomy offered here should be addressed. First, someone might object that the formulation of source incompatibilism offered above-(SI-5) - is too broad to be useful, since it includes most, and quite possibly all, incompatibilists. To the charge that all incompatibilists will count as source incompatibilists on the above taxonomy, the plea is not guilty. Incompatibilists who think that determinism does not rule out sourcehood will not count as source incompatibilists. Perhaps the only problem with determinism, according to such a theorist, is that it robs us of the ability to do otherwise. Mere lack of this ability, however, need not imply lack of sourcehood. ${ }^{23}$ As to the charge that most incompatibilists will count as source incompatibilists on the above taxonomy, the plea is guilty, but why is this a problem? Source incompatibilism is an incredibly plausible version of incompatibilism. Moreover, there will still be the distinction, even among source incompatibilists, between those who are also leeway incompatibilists and those who aren't, as well as other similar distinctions between other varieties of incompatibilism.

This last point leads to the next objection, which is that the above taxonomy eliminates the useful contrast between source incompatibilism and leeway

incompatibility of divine foreknowledge and human freedom (Pike 1965). This argument purports to show that divine foreknowledge (of a certain sort) is incompatible with the ability to do otherwise, but the argument seems to have no implications whatever for the issue of sourcehood. So, it's surely possible to be a leeway incompatibilist about determinism and moral responsibility without thinking that determinism would also rule out sourcehood. (Conversely, it's possible to be worried about the implications of determinism for sourcehood without being worried about its implications for the ability to do otherwise, even while accepting the truth of (PAP).)

${ }^{22}$ Indeed, Robert Kane is a theorist who endorses (LI), (SI), and (UI).

${ }^{23}$ See footnote 21 . Alternatively, it may be that most actual theorists who worry about the ability to do otherwise are worried precisely because they think that sourcehood requires such an ability. It's unclear how to judge this possibility, but in any case, all that's needed for the purposes of this paper is that theorists who worry about the ability to do otherwise need not have any worries about sourcehood. 
incompatibilism. If one adopts the taxonomy of this paper, one can no longer conclude $\sim(\mathrm{LI})$ from (SI) or vice versa. While this is true, it seems unproblematic. Indeed, I argued above that the only reason (SI) and (LI) were thought to be mutually exclusive was that extraneous claims were being smuggled into formulations of the two views. (SI) should not include the claim, for example, that (PAP) is false, since that claim has nothing to do with incompatibilism per se. Once talk about (PAP) is excluded from a proper formulation of (SI), however, the dichotomy between (SI) and (LI) disappears. Far from being an unwanted consequence, however, this provides a clearer picture of the incompatibilist neighborhood. Any particular variety of incompatibilism provides a reason why one might think that determinism and moral responsibility could not obtain in the same world, and there very well could be more than one reason to think that.

\section{CONCLUSION}

Source incompatibilism is misunderstood. This paper is an attempt to get clear on just how this thesis should be formulated, and on how it differs from neighboring theses, such as leeway incompatibilism and ultimacy incompatibilism. Dividing up the terrain in the way suggested above has three chief virtues:

(1) It respects the constraint that any sort of incompatibilism should be a genuine type of incompatibilism that specifically references why the incompatibilist thesis is true. In so doing, it respects the difference between reasons why a theorist might accept incompatibilism and further positive conditions a theorist might put on moral responsibility.

(2) It shows that the different incompatibilist positions are not mutually exclusive. One can be both a leeway incompatibilist and a source incompatibilist, and perhaps other types of incompatibilist as well (such as a Transfer-of-Non-Responsibility incompatibilist, for instance).

(3) It clearly brings out the fact that all theorists agree that moral responsibility requires some notion of sourcehood.

I have not provided any arguments either in favor of or against source incompatibilism. Rather, the project was to discover the most conceptually perspicuous formulation of the thesis. To the extent that the project has succeeded, theorists of all stripes will be in a better position to begin serious investigation into the pressing question of whether source incompatibilism is true. ${ }^{24}$

\footnotetext{
${ }^{24}$ For helpful conversations about and comments on this essay, thanks to John Martin Fischer, Paul
} Hoffman, Michael Nelson, Kevin Timpe, Patrick Todd, and Gary Watson. 
Neal A. Tognazzini

The College of William \& Mary

Dept. of Philosophy, PO Box 8795

Williamsburg, VA 23187-8795 USA

E-Mail: natognazzini@wm.edu

References

Campbell, Joseph. 2006. "Farewell to Direct Source Incompatibilism." Acta Analytica 21 (4): 3649.

2011. Free Will. Cambridge: Polity Press.

Clarke, Randolph. 2003. Libertarian Accounts of Free Will. Oxford: Oxford University Press.

Fischer, John Martin. 1982. "Responsibility and Control." The Journal of Philosophy 79 (1): 2440.

1994. The Metaphysics of Free Will: An Essay on Control. Oxford: Blackwell. 2006. "Free Will and Moral Responsibility." In his My Way: Essays on Moral Responsibility, 182-216. Oxford: Oxford University Press.

Fischer, John Martin \& Mark Ravizza. 1998. Responsibility and Control: A Theory of Moral Responsibility. Cambridge: Cambridge University Press.

Fischer, John Martin, Robert Kane, Derk Pereboom, \& Manuel Vargas. 2007. Four Views on Free Will. Cambridge, MA: Blackwell.

Frankfurt, Harry. 1969. "Alternate Possibilities and Moral Responsibility." The Journal of Philosophy 66 (3): 829-839.

2002. "Reply to John Martin Fischer." In Contours of Agency: Essays on Themes from Harry Frankfurt, edited by Sarah Buss \& Lee Overton, 27-31. Cambridge, MA: MIT Press.

2006. Taking Ourselves Seriously \& Getting it Right. Stanford, CA: Stanford University Press.

Kane, Robert. 1996. The Significance of Free Will. Oxford: Oxford University Press.

Leon, Felipe \& Neal Tognazzini. 2010. "Why Frankfurt-Examples Don't Need to Succeed to Succeed." Philosophy and Phenomenological Research 80 (3): 551-565.

Lewis, David. 1981. “Are We Free to Break the Laws?” Theoria 47 (3): 113-21.

McKenna, Michael. 2001. "Source Incompatibilism, Ultimacy, and the Transfer of NonResponsibility.” American Philosophical Quarterly 38 (1): 37-52.

O'Connor, Timothy. 2000. Persons and Causes: The Metaphysics of Free Will. Oxford: Oxford University Press.

Pereboom, Derk. 2001. Living Without Free Will. Cambridge: Cambridge University Press. 2006. "Reasons-Responsiveness, Alternative Possibilities, and Manipulation Arguments Against Compatibilism: Reflections on John Martin Fischer's My Way." Philosophical Books 47 (3): 198-212.

. 2008. "Defending Hard Incompatibilism Again." In Essays on Free Will and Moral Responsibility, edited by Nick Trakakis \& Daniel Cohen, 1-33. Cambridge: Cambridge Scholars Press.

Pike, Nelson. 1965. "Divine Omniscience and Voluntary Action.” The Philosophical Review 74 (1): 27-46.

Ravizza, Mark. 1994. "Semi-Compatibilism and the Transfer of Non-Responsibility." Philosophical Studies 75 (1-2): 61-93.

Strawson, Galen. 1986. Freedom and Belief. Oxford: Clarendon Press.

Stump, Eleonore. 2003. "Moral Responsibility Without Alternative Possibilities." In Moral Responsibility and Alternative Possibilities: Essays on the Importance of Alternative Possibilities, edited by Michael McKenna \& David Widerker, 139-158. Aldershot: Ashgate.

Timpe, Kevin. 2007. "Source Incompatibilism and Its Alternatives." American Philosophical Quarterly 44 (2): 143-155.

2008. Free Will: Sourcehood and Its Alternatives. London: Continuum.

van Inwagen, Peter. 1983. An Essay on Free Will. Oxford: Clarendon Press.

2008. "How to Think About the Problem of Free Will." The Journal of Ethics 12

(3/4): 327-341. 